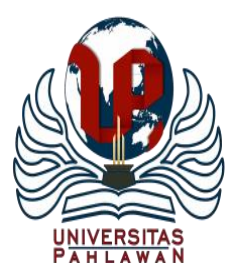

Jurnal Abdidas Volume 2 Nomor 1 Tahun 2021 Halaman 127-134

JURNAL ABDIDAS

http://abdidas.org/index.php/abdidas

\title{
Pelatihan Pengelolaan Kas dan Hutang dalam Financial Report pada Masyarakat Perumahan Buana Bukit Permata Blok Mutiara
}

\author{
Dian Efriyenty \\ Program Studi Akuntansi, Fakultas Ilmu Sosial dan Humanioura, Universitas Putera Batam, Indonesia \\ E-mail : dianefriyenty@gmail.com
}

\begin{abstract}
Abstrak
Berdasarkan fenomena terhadap usaha mikro kecil dan menengah yang tidak produktif, dalam menggunakan penerimaan dan pengeluaran kas dalam laporan keuangan. Pengabdian dilakukan dengan tujuan untuk dapat membantu masyarakat Perumahan Buana Bukit Permata Bolk Mutiara untuk mekanisme pelaporan keuangan dalam mengelola kas dan utang. Metode yang digunakan survei lapangan dan wawancara serta latihan. Adapun sasaran program adalah mengacu kepada ibu-ibu yang berjumlah 16 orang usaha kecil menengah (UKM) di Perumahan buana bukit permata blok mutiara. Hasil kegiatan pengabdian pemilik UKM memahami dalam pembuatan laporan keuangan yang sesuai dengan SAK ETAP serta mengendalikan kas dan hutang dengan membuat pembukuan sederhana dalam pengklasifikasian penerimaan dan pengeluaran kas. Dalam kegiatan pelatihan tersebut masih banyak ibu-ibu pemilik UKM yang belum memahami bagaimana bentuk laporan keuangan yang sesuai dengan SAK ETAP dan belum memahami pengklasifikasian untuk pembukuan penerimaan dan pengeluaran kas. Berdasarkan pelatihan yang telah dilakukan pada UKM di Perumahan Bukit Permata Blok Mutiara dalam hal ini peserta yang berjumlah 16 orang diharapkan dapat memberikan dampak yang positif kepada Dosen Pengabdi yang melakukan pelatihan dalam pemahaman terhadap laporan keuangan serta pengklasifikasian untuk pembukuan penerimaan dan pengeluaran kas yang diberikan kepada peserta tersebut.
\end{abstract}

Kata kunci: pengelolaan kas, hutang, financial report

Abstract

Based on the phenomenon of unproductive micro, small and medium enterprises, in using cash receipts and disbursements in financial reports. This service is carried out with the aim of being able to help Buana Bukit Permata, Permata, Mutiara Housing community for financial reporting mechanisms in managing cash and debt. The methods used were field surveys and interviews and exercises. The target of the community service program is to refer to 16 mothers of small and medium enterprises (SMEs) in Buana Bukit Permata Blok Mutiara Housing. The results of the service activities of SMEs owners understand in making financial reports in accordance with SAK ETAP and controlling cash and debt by making simple bookkeeping in the classification of cash receipts and payments. In these training activities, there are still many women SMEs owners who do not yet understand how to form financial reports in accordance with SAK ETAP and do not yet understand the classification for accounting of cash receipts and payments. Based on the training that has been carried out on SMEs at the Bukit Permata Blok Mutiara Housing, in this case the participants totaling 16 people are expected to have a positive impact on the Community Service Lecturer Team who carry out training in understanding financial reports and classification for accounting of cash receipts and disbursements these participants.

Keywords: cash management, accounts payable, financial report

Copyright (c) 2021 Dian Efriyenty

$\triangle$ Corresponding author

Address : Universitas Putera Batam

Email : dianefriyenty@gmail.com

DOI : https://doi.org/10.31004/abdidas.v2i1.226

ISSN 2721- 9224 (Media Cetak)

ISSN 2721- 9216 (Media Online)

Jurnal Abdidas Vol 2 No 1 Tahun 2021 p-ISSN 2721-9224 e-ISSN 2721-9216 
128 Pelatihan Pengelolaan Kas dan Hutang dalam Financial Report pada Masyarakat Perumahan Buana Bukit Permata Blok Mutiara - Dian Efriyenty

DOI: https://doi.org/10.31004/abdidas.v2i1.226

\section{PENDAHULUAN}

Kehidupan dikelola untuk dapat mencukupi kebutuhan keuangan keluarga dan memanajemen keuangan dengan baik. Kebutuhan manusia beraneka ragam yaitu dengan pilihan hidup terpenuhi sesuai dengan pemenuhan kebutuhannya (Maseko, 2011).

Kebutuhan manusia itu tidak terbatas. Namun kebutuhan manusia pelu dikelola dengan baik agar tidak terjadi masalah financial yang merugikan banyak pihak. Ibu-ibu di Perumahan Blok Mutiara termasuk golongan usia yang produktif untuk penggerak perekonomian Indonesia. Jiwa kewriausahaan yang damping oleh ilmu pengetahuan yang cukup serta keterampilan, namun sifat konsumtif dan gelap mata untuk tertarik membeli tidak terlepaskan (Salmiah, 2015).

Pada umumnya pendapatan masyarakat hanya digunakan untuk membiayai kebutuhankebutuhan jangka pendeknya, seperti belanja kebutuhan bulanan, rekening listrik, rekening telepon, transportasi, uang pembayaran sekolah, dan lain-lain. Padahal sebenarnya kebutuhan keluarga tidak hanya itu saja. Ada kebutuhan lain yang kurang dipikirkan oleh masyarakat yang juga merupakan sama pentingnya dengan kebutuhankebutuhan jangka pendek tersebut. Dalam hal ini kurang mengendalikan pengeluaran-pengeluaran yang bersifat berlebihan seperti, belanja baju, shopping, nonton dan lain sebagainya. Sehingga dapat menyebabkan hutang di dalam ruang lingkup rumah tangga (Maseko, 2011).

Fenomena hidup glamor dan gaya hidup konsumtif dalam rumah tangga, menjadikan sulit memanage rumah tangga. Begitupun masalahmasalah pengelolaan keuangan pribadi dan pengelolaan utang. Tanpa pengelolaan yang tidak tepat terhadap kas, berapa pun uang yang kita miliki akan cepat habis untuk membeli segala kebutuhan. Serta meminamilisir pengeluaranpengeluaran yang menimbulkan utang di kehidupan rumah tangga. Bahkan pengetahuan dari cara mengelola kas dan hutang serta membuat laporan keuangan masih kurang bagi masyarakat khususnya di perumahan buana Bukit Permata Blok Mutiara. Hal ini dikarenakan pelaku usaha banyak yang belum memahami pencatatan laporan keuangan terkait dengan penerimaan dan pengendalian pengeluaran kas. Serta berdasarkan hasil survey, banyaknya ibu-ibu pelaku UKM tidak menerapkan standar akuntansi keuangan entitas tanpa akuntabilitas publik.

Berdasarkan hasil penelitian (Hidayatulloh et al., 2019) Peningkatan akuntabilitas keuangan kelompok UMKM Aisyiah Bantul melalui pelatihan pembukuan dan perpajakan, dengan hasil penelitiannya. Langkah-langkah dalam pengabdian ini merupakan tahap sosialisasi mengenai pentingnya laporan keuangan, Tahap kedua memberikan pelatihan tentang mempersiapkan keuangan dengan menggunakan Microsoft Excel dalam proses penunjang dalam pengendalian kas dan utang, tujuannya untuk memberikan sosialisasi kepada UMKM tentang Peraturan Pemerintah Nomor 23 Tahun 2018.

Berdasarkan penelitian (Citra Sukmadilaga, Sudrajat sudrajat et al., 2018) Pelatihan penyusunan laporan keuangan bagi perusahaan start up binaan Digital Lounge (Dilo) PT. Telkom 
129 Pelatihan Pengelolaan Kas dan Hutang dalam Financial Report pada Masyarakat Perumahan Buana Bukit Permata Blok Mutiara - Dian Efriyenty

DOI: https://doi.org/10.31004/abdidas.v2i1.226

Bandung dengan hasil melihat kondisi tersebut maka dirasa perlu untuk memberikan pendampingan dan pelatihan dalam penyusunan laporan keuangan pada UMKM di Kota Bandung khususnya bagi UMKM yang bergerak di bidang digital.

Berdasarkan penelitian (I.B.K. Surya, I.K. Mustanda, N. Abundanti, A.A.A. Sriathi, N.W. Mujiati \& Utama, 2017) Pelatihan dan Pendampingan Akuntansi dan Perlakuan Keuangan bagi Pengurus dan Staf LPD Desa Adat Lukluk serta Usaha Mikro, hasil pelatihan menunjukkan bahwa Peserta serius dalam mengikuti pelatihan, ditunjukkan dengan aktif berdiskusi tentang permasalahan yang dihadapi. Hal ini sangat berakibat penting untuk pengelolaan keuangan usaha

Hasil penelitiannya (Indrayeni, Fitria Rahmi, 2019) terkait dengan Pelatihan Penyusunan Laporan Keuangan pada Badan Usaha Milik Nagari Mitra Palaluar Madani, selama pelatihan ditemukan bahwa laporan keuangan yang disusun oleh Bumnag tidak sesuai dengan standar yang berlaku. Selain itu, Bumnag juga belum menyusun laporan perubahan ekuitas. Maka dari itu pentingnya pendampingan laporan keuangan. Tujuan pengabdian ini adalah untuk memberikan manfaat ilmu pengetahuan kepada pelaku usaha di Perumahan Mutiara, terkait dengan pencatatan dan pengendalian kas dan hutang.

\section{METODE}

Pelatihan bagi masyarakat Buana Bukit Permata Blok Mutiara di kota Batam akan dilaksanakan pada tanggga 10 Maret dan 6
Agustus 2020, Pukul 16.00 WIB, Pelatihan ini bertempat di Vasum Perumahan Buana Bukit Permata Blok Mutiara di kota Batam.

Metode yang diberikan dalam pengabdian terdiri dari lima langkah diantaranya:

1. Langkah awal dosen pengabdi Dian Efriyenty datang ke lokasi perumahan Mutiara tanggal 10 Maret 2020.

Pengabdi melakukan kunjungan dan peninjauan di Buana Bukit Permata Blok Mutiara di kota Batam dan melakukan survei mengenai permasalahan terkait cara mengendalikan kas dan hutang pada ibu-ibu rumah tangga di Perumahan Buana Bukit Permata Blok Mutiara di kota Batam.

2. Pengabdi memberikan gambaran umum mengendalikan kas dan hutang yaitu dengan menganalisis anggaran belanja di usaha kecil menegah, mencatat pengeluaran dan pemasukan dalam satu bulan.

3. Meningkatkan keuntungan. Tim usaha kecil menegah bisa bekerja lembur, melakukan pekerjaan musim.

4. Kurangi pengeluaran yang mengakibatkan timbulnya utang di lembaga perbankan. Belilah barang yang diperlukan tidak sekedar keinginan, mengurangi pengeluaran yang tidak penting dan menghemat listrik dan air.

5. Analisis tidakan utang mulai dipraktek kan Kembali di sesi terakhir tanggal 6 Agustus 2020. Pada saat pertama dalam mengambil keputusan utang perhatikan suku bunganya. Jika sudah terikatnya utang di perbankan maka yang dilakukan masa jatuh temponya, bunga 
130 Pelatihan Pengelolaan Kas dan Hutang dalam Financial Report pada Masyarakat Perumahan Buana Bukit Permata Blok Mutiara - Dian Efriyenty

DOI: https://doi.org/10.31004/abdidas.v2i1.226

yang harus dibayarkan, bahkan lebih selektif bunga yang rendah lebih kecil resiko.

Evaluasi kegiatan pengabdian ini untuk meningkatkan pemahaman para pelaku UMKM terkait dengan pencatatan kas dan hutang maupun pengendaliannya. Adapun detail evaluasi kegiatan pengabdiannya ini dibawah ini:

1. Tujuan: mengendalikan kas dan hutang khususnya pada rumah tangganya.

Indikator capaian: penguasaan akuntansi dengan mudah dan cepat akan memberikan manfaat bagi mereka dalam hal pengelolaan keuangan usaha dan pengendalian kas dan hutang pada keuangan usaha maupun pribadi.

Tolak ukur: UMKM mampu menyusun laporan keuangan dalam pengendalian kas dan hutang.

2. Tujuan: berkurangnya kas sehingga mengakibatkan diperlukannya pinjaman di lembaga perbankan untuk meneruskan pengembangan usaha kecil menegah.

Indikator capaian : Diberikan Pelatihan dalam memahami dan membuat laporan keuangan, analisis tersebut akan dilakukan terhadap kas dan utang.

Tolak ukur: ibu-ibu UKM Bukit Permata memahami pencatatan pengelolaan kas dalam kegiatan usaha.

Keberlanjutan Kegiatan

1. Kegiatan Pengabdian ini merupakan pengabdian jenis pelatihan dengan adanya manfaat yang diperoleh masyarakat diharapkan pengabdian ini akan berlanjut untuk semua blok yang ada di legenda bali tidak hanya untuk blok D tapi meluas keseluruh kawasan masyarakat.
2. Karyawan pedagang usaha kecil menegah diharapkan mampu untuk masa yang akan datang bekerja secara mandiri dan mampu mengendalikan kas dan hutang dalam financial report.

\section{HASIL DAN PEMBAHASAN}

Pengabdian ini dilakukan pada hari Selasa, 10 Maret 2020 dan 6 Agustus 2020 yang bertempat di Perumahan Bukit Permata Blok Mutiara. Kegiatan pengabdian ini dilaksanakan dalam bentuk Pelatihan membuat laporan keuangan pada UKM Ibu-ibu rumah tangga di Perumahan Bukit Permata Blok Mutiara. Pada awal acara pembukaan acara disampaikan oleh Ketua RT Perumahan Bukit Permata Blok Mutiara, setelah itu di lanjutkan untuk penyampaian bahan materi laporan keuangan pertama, setelah itu dilanjutkan dengan penutupan bahan materi laporan keuangan.

Pada laporan pengabdian ini, pengabdi menjelaskan bagaimana penyusunan laporan keuangan sesuai standar. Kegiatan pelatihan ini dimaksudkan untuk mengajak pemilik UKM memahami dalam penyusnan pembukuan usaha dengan SAK-EMKM serta mengendalikan kas dan hutang dengan membuat pembukuan sederhana dalam pengklasifikasian penerimaan dan pengeluaran kas. Dalam kegiatan pelatihan tersebut masih banyak ibu-ibu pemilik UKM yang belum memahami bagaimana bentuk penyusunan laporan keuangan dengan standar akuntansi dan belum memahami pengklasifikasian untuk pembukuan penerimaan dan pengeluaran kas. Dalam kegiatan pelatihan tersebut, para UKM 
131 Pelatihan Pengelolaan Kas dan Hutang dalam Financial Report pada Masyarakat Perumahan Buana Bukit Permata Blok Mutiara - Dian Efriyenty

DOI: https://doi.org/10.31004/abdidas.v2i1.226

memiliki minat yang sangat tinggi mengenai, maka pengelolaan keuangan sesuai dengan standar para UKM tersebut memiliki antusias yang sangat tinggi dalam kegiatan tersebut. Adapun penjelasan pada setiap pertemuan sebagai berikut.

\section{Pertemuan Pertama}

Pelaksanaan pengabdian masyarakat pertemuan pertama dilaksanakan pada Selasa, 10 Maret 2020, dimana kegiatan pertemuan saat itu diawali dengan pembukaan oleh Ketua, dilanjutkan penyampaian materi topik materi Pengantar Akuntansi UMKM dan dasar-dasar akuntansi.

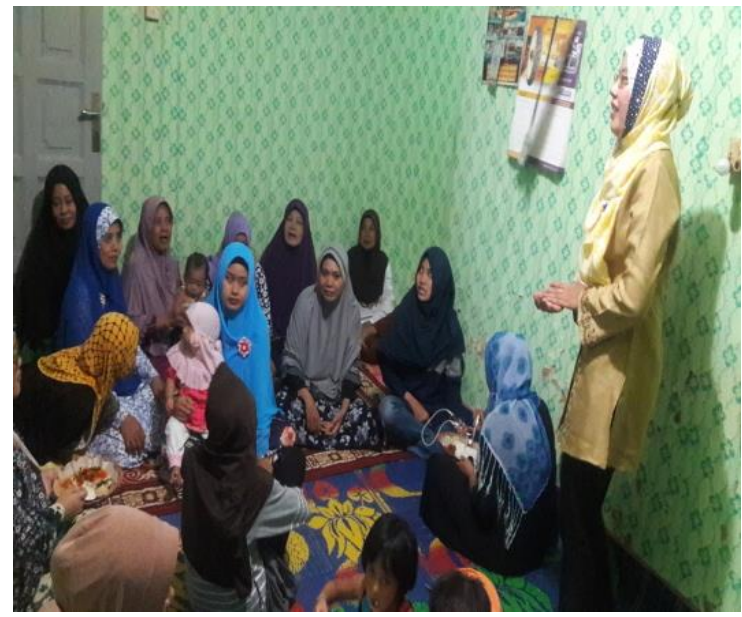

Gambar 1. Sosialisasi Laporan Keuangan UMKM dan Siklus Akuntansi

\section{Pertemuan Kedua}

Pelaksanaan pengabdian masyarakat pertemuan kedua dilaksanakan pada Kamis, 6 Agustus 2020. Kegiatan pertemuan ini berupa penjelasan topik praktik pencatatan penerimaan kas dan pengeluaran kas untuk kegiatan usaha maupun pribadi. Serta ditutup pengabdian ini dengan Latihan pencatatan keuangan penerimaan kas dan pengeluaran kas. Kemudian dilengkapi dengan diskusi terkait permasalahan yang dihadapi ibu-ibu pelaku usaha di perumahan Bukit Permata.

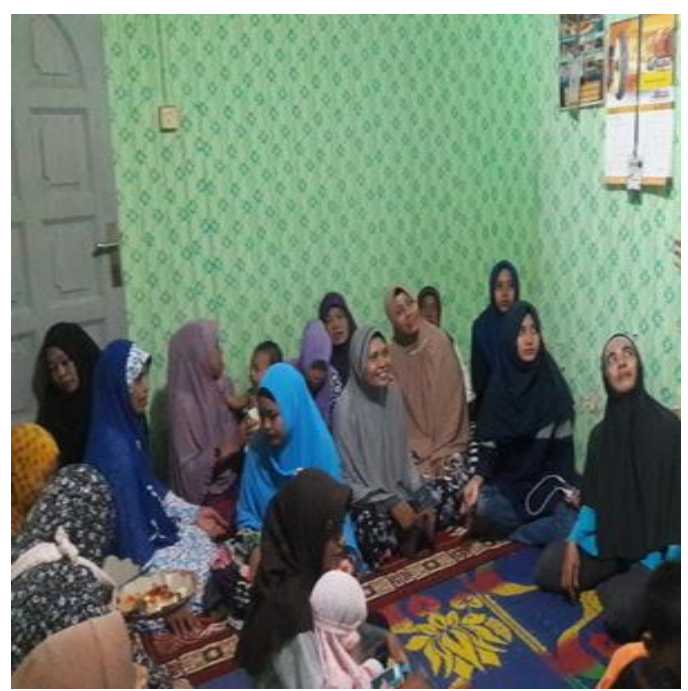

Gambar 2. Praktek Pengelolaan Kas dan Hutang dalam usaha.

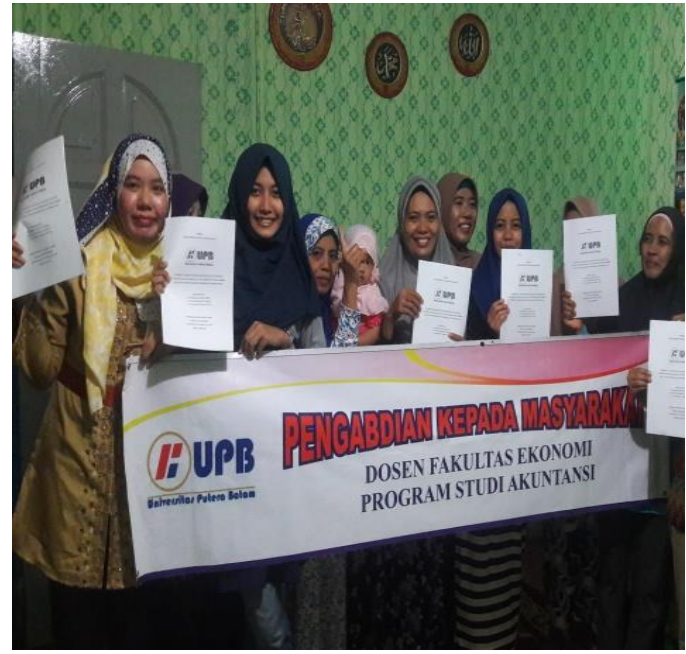

Gambar 3. Foto Bersama dengan Peserta Pengabdian

Berdasarkan pelatihan yang telah dilakukan pada UKM di Perumahan Bukit Permata Blok Mutiara dalam hal ini peserta yang berjumlah 16 orang diharapkan dapat memberikan dampak yang positif kepada Pengabdi yang melakukan pelatihan dalam pemahaman terhadap laporan keuangan 
132 Pelatihan Pengelolaan Kas dan Hutang dalam Financial Report pada Masyarakat Perumahan Buana Bukit Permata Blok Mutiara - Dian Efriyenty

DOI: https://doi.org/10.31004/abdidas.v2i1.226

serta pengklasifikasian untuk pembukuan penerimaan dan pengeluaran kas yang diberikan kepada peserta tersebut. Dalam hal ini para peserta menikmati dan mempunyai minat yang tinggi untuk menghadiri kegiatan selanjutnya, jika ada melakukan suatu pembinaan terhadap pemahaman pada pembukuan keuangan sesuai SAK-EMKM pada Perumahan Bukit Permata Blok Mutiara. Serta terjalinnya kekeluargaan dan tim work dalam menstranfer knowledge.Berdasarkan hasil evaluasi pengabdian ini : Materi pertama diisi dengan penguatan pentingnya akuntansi bagi usaha kecil (UMKM) dan data-data transaksi yang harus dimasukan didalam jurnal umum. Pada sesi ini terjadi diskusi yang menarik antara audience dengan pemateri mengenai konsep dasar usaha terkait usaha yang UKM tekuni. Kemudian dilanjutkan dengan siklus akuntansi.

Pembinaan hari kedua dilaksanakan hari Kamis, 6 Agustus 2020, peserta diberikan gambaran tentang materi dan praktik laporan keuangan yang terdiri dari laporan laba rugi, laporan perubahan ekuitas, laporan neraca serta laporan arus kas. Pada sesi awal peserta bertanya dan berdiskusi tentang transaksi dan pencatatan yang telah mereka buat. Kemudian dilanjutkan sesi praktek penerimaan kas dan pengeluaran kas untuk mencatat keuangan pribadi.

Pelaksanaan pengabdian yang dilaksanakan ditemukan kendala yang signifikan, namun dapat diatasi setelah kegiatan dilaksanakan sampai selesai, kendala yang terjadi adalah:

1. Sebagian besar peserta menyusun laporan keuangan belum sesuai standar akuntansi

keuangan entitas tanpa akuntabilitas publik.

2. Kesulitan mencocokan waktu Dosen Pengabdi dengan peserta pengabdian.

3. Laporan keuangan yang telah biasa disusun oleh UKM tidak bisa diganti secara langsung.

4. Keikutsertaan atau kehadiran peserta yang relative rendah hanya 20 orang dari 16 orang undangan yang telah dikoordinir.

Permasalahan yang dihadapi Dosen Pengabdi diatas dapat dievaluasi dengan cara sebagai berikut:

1. Pelaksanaan ini dapat dijelaskan secara continue, sampai dengan usaha kecil menengah mengerti dengan penjelasan setiap pertemuan yang dilaksanakan sampai dengan penerapan laporan keuangan dalam kegiatan rutin pada usaha ibu-ibu perumahan Bukit Permata.

2. Pengabdi memberikan gambaran pengendalian kas dan hutang, maka dari itu berdasarkan hasil pengabdian ibu-ibu perumahan Bukit Permata sudah mulai menyesuaikan pencatatan penerimaan kas dan pengeluaran kas dalam proses pengendalian keuangan usaha.

3. Ibu-ibu meningkatkan keuntungan, sesuai dengan tujuan ibu-ibu perumahan Bukti Permata, melakukan penjualan musiman namun dilakukan juga penjualan di warung-warung maupun media online.

4. Kurangi pengeluaran yang menyebabkan pengeluaran bertambah. Ibu-ibu perumahan telah mencatat pengeluaran 
133 Pelatihan Pengelolaan Kas dan Hutang dalam Financial Report pada Masyarakat Perumahan Buana Bukit Permata Blok Mutiara - Dian Efriyenty

DOI: https://doi.org/10.31004/abdidas.v2i1.226

serta mengurangi pengeluaran yang tidak penting.

5. Analisis Tindakan utang. Ibu-ibu perumahan Bukit Permata mulai memikirkan dampak yang diterapkan jika melakukan pinjaman di lembaga perbankan. Seperti halnya suku bunga rendah resiko dan jatuh tempo dari tingkat pengembalian pinjaman.

Dosen pengabdi selalu melakukan koordinasi dan berkomunikasi serta mengevaluasi setiap selesai kegiatan pengabdian masyarakat. Pelaksanaan evaluasi kegiatan dilakukan untuk mengetahui kendala yang dihadapi saat pengabdian dilaksanakan. Hasil evaluasi akan ditindaklanjuti sesuai dengan kendala yang sedang dihadapi.

\section{SIMPULAN}

Adapun beberapa kesimpulan dalam

Pengabdian ini :

1. Ibu-ibu perumahan Blok Mutiara telah memahami pentingnya penyusunan laporan keuangan usaha yang benar.

2. Para peserta telah mengerti dalam penyusunan atau pembuatan mulai dokumen transaksi sampai dengan pembuatan laporan keuangan usaha serta pengklasifikasian untuk pembukuan penerimaan dan pengeluaran kas yang diberikan kepada peserta tersebut sehingga peserta dapat mengendalikan kas dan hutang untuk perkembangan usahanya.

3. Para peserta mengharapkan adanya pembinaan yang berkelanjutan.

\section{UCAPAN TERIMAKASIH}

Pengabdi berterima kasih kepada LPPM yang telah mendanai pengabdian ini, serta kepala LPPM yang selalu mensuport pengabdian dosen.

\section{DAFTAR PUSTAKA}

Agustin, Y., Setianingsih, S., \& Santoso, Y. D. (2019). Pelatihan penyusunan laporan keuangan bagi entitas mikro, kecil dan menengah bidang usaha dagang pada UMKM Binaan Pusat Inkubasi Bisnis Syariah. Journal Intervensi Komunitas, 1(1), 1-13. https://doi.org/ISSN: 2714-691X

Citra Sukmadilaga, Sudrajat sudrajat, U. K., Lestari, Utami, T., Devi, Candra, M., \& Ardian. (2018). Pelatihan Penyusunan Laporan Keuangan Untuk Start Up Company Binaan Digital Lounge (Dilo) PT. Telkom Bandung. Jurnal Aplikasi Ipteks Untuk Masyarakat, 7(3), 209-212.

Hidayatulloh, A., Ainy, R. N., \& Nafiati, L. (2019). Peningkatan akuntabilitas keuangan kelompok UMKM 'Aisyiah Bantul melalui pelatihan pembukuan dan perpajakan. Jurnal Abdimas BSI, 1(2), 681-686.

I.B.K. Surya, I.K. Mustanda, N. Abundanti, A.A.A. Sriathi, N.W. Mujiati, W. M., \& Utama, A. A. S. K. D. (2017). Pelatihan dan Pendampingan Tentang Perlakuan Akuntansi dan Keuangan Bagi Manajemen Dan Staf LPD Desa Adat Lukluk. Jurnal ABDIMAS Unmer Malang, 16(3), 352-355.

Indrayeni, Fitria Rahmi, R. (2019). Pelatihan Penyusunan Laporan Keuangan Pada Badan Usaha Milik Nagari Mitra Palaluar Madani. Jurnal Pengabdian Masyarakat Multidisiplin, 3(2), 121-130. https://doi.org/E-ISSN: 2614-7106

Maseko, M. (2011). Accounting Practices of SMES in Zimbabwe: An Investigative Study of Record Keeping for Performance Measurement. Journal of Accounting and TaxationNo Title. Journal of Accounting and Taxation, 3(8), 171-181. https://doi.org/10.5897/JAT.11031 
134 Pelatihan Pengelolaan Kas dan Hutang dalam Financial Report pada Masyarakat Perumahan Buana Bukit Permata Blok Mutiara - Dian Efriyenty

DOI: https://doi.org/10.31004/abdidas.v2i1.226

Salmiah, I. (2015). Analisis Penerapan Akuntansi dan Kesesuaiannya dengan Standar Akuntansi Keuangan Entitas Tanpa Akuntabilitas Publik Pada UMKM Kota Pekanbaru. Jurnal Akuntansi, 3(2), 11-19. 